www.jmscr.igmpublication.org

Impact Factor (SJIF): 6.379

Index Copernicus Value: 71.58

ISSN (e)-2347-176x ISSN (p) 2455-0450

crossref DOI: _https://dx.doi.org/10.18535/jmscr/v6i4.142

Journal Of Medical Science And Clinical Research

\title{
A Retrospective Study Evaluating the Anterior Bone Wall Thickness Using Cone Beam Computed Tomography Images with a Three Dimensional Software
}

\author{
Authors \\ Dr Priyadershini Rangari ${ }^{1}$, Dr Udaybhan Singh ${ }^{2}$, Dr Nivedita Singh ${ }^{3}$, \\ Dr Ashish Dewangan ${ }^{4}$ \\ ${ }^{1}$ Assistant Professor, Department of Dentistry, Sri Shankaracharya Medical College, Bhilai, Durg, \\ (Chhattisgarh), India \\ ${ }^{2}$ MDS (Oral and Maxillofacial Surgery), BDS, FAM, (Germany) FICOI (USA), DICOI (USA), Delhi, India \\ ${ }^{3}$ MDS (Oral Medicine and Radiology), Meerut, (U.P.) India \\ ${ }^{4} \mathrm{MDS}$, (Prosthodontics) Associate Professor and Head, Department of Dentistry, Sri Shankaracharya \\ Medical College, Bhilai, Durg, (Chhattisgarh), India \\ Corresponding Author \\ Dr Ashish Dewangan \\ B-7/1, Chouhan Green Valley, Junwani, Bhilai, Dist. Durg, Chhattisgarh, Pin Code 490020 \\ Email: drpriyakasture@gmail.com
}

\begin{abstract}
The aim of the study was to analyze the thickness of the facial bone wall at teeth in the anterior maxilla based on cone beam computed tomography (CBCT) images, since this anatomical structure is important for the selection of an appropriate treatment approach in patients undergoing post extraction implant placement.

Three dimensional (3D) images were reconstructed using cone-beam computed tomography (CBCT) scans from 45 Indian subjects of age group ranging between20-55 years, with a sample size of 90 teeth using On Demand 3D software. The thickness of the facial bone wall in the respective sagittal scan was measured perpendicular to the long axis of the tooth at two locations: at the crest level and at the middle of the root.

Mean thickness of buccal plate $3 \mathrm{~mm}$ below CEJ was $0.59 \pm 0.27 \mathrm{~mm}$ at central incisor, $0.69 \pm 0.54 \mathrm{~mm}$ at lateral incisor, and $1.05 \pm 0.75 \mathrm{~mm}$ at canine. Mean thickness of palatal plate $3 \mathrm{~mm}$ below CEJ was 1.23 $\pm 0.45 \mathrm{~mm}$ of central incisor, $1.04 \pm 0.59 \mathrm{~mm}$ of lateral incisor, $1.49 \pm 0.61 \mathrm{~mm}$ of canine. Mesio-distal diameter $3 \mathrm{~mm}$ below CEJ was $4.66 \pm 0.39 \mathrm{~mm}$ of central incisor, $4.09 \pm 0.45 \mathrm{~mm}$ of lateral incisor, and $5.27 \pm 0.52 \mathrm{~mm}$ of canine. Buccal bony curvature angle below root apex was $114 \pm 16.5$ at central incisor, $144.0 \pm 12.9$ at lateral incisor, $145.0 \pm 8.9$ at canine. Distance between root apex and the deepest point of buccal bony curvature of central incisor was $3.49 \pm 1.17 \mathrm{~mm}$ at central incisor, $3.49 \pm 1.17 \mathrm{~mm}$ at lateral incisor, and $5.51 \pm 1.66 \mathrm{~mm}$ at canine.

Conclusion for the study was that, there was a statistically significant increase in facial bone wall thickness from the central incisors to the canine. The facial bone wall in the crestal area of teeth in the anterior maxilla was either missing or thin in roughly all of patients.

Keywords: anterior maxilla, facial bone thickness, implant placement, cone beam computed tomography.
\end{abstract}




\section{Introduction}

The long-term stability of osseo-integration is not equivalent to successful implantation at the maxillary anterior region. Apart from the traditional criteria, an optimal esthetic outcome has become another challenge for clinicians operating at this region. From the perspective of dental implant esthetics, the incidence and severity of soft tissue recession occurring labially and inter proximally should be a major concern and has already been the focus of numerous studies. ${ }^{[1]}$

Conventional radiographs, such as cephalometric and panoramic radiographs, are not appropriate for examining buccal bone or periodontal changes during and after implant therapy. These techniques are based on a two-dimensional representation of a three-dimensional (3D) object and do not allow the operator to evaluate facial bone widths.

Implant placement following extraction is commonly encountered in daily practice. In the anterior maxilla, it presents a considerable challenge to clinicians because of the high esthetic expectations of patients and, at the same time, various local risk factors that can potentially compromise the predictability of treatment outcomes. ${ }^{(2-4)}$ The thickness of the facial bone wall in the anterior maxilla is of crucial importance for the selection of the appropriate treatment approach. Today, immediate ${ }^{[5,6]}$ or early ${ }^{[7,8]}$ implant placement is used mainly to increase the attractiveness of implant therapy. In the anterior maxilla, the facial bone wall is often thin or lacking, a result of the facial position of anterior teeth, 8 and undergoes substantial resorption following tooth extraction. ${ }^{[10,11]}$ After implant bed preparation, the facial bone wall should ideally measure at least $2 \mathrm{~mm}$ in thickness to ensure proper soft tissue support and to avoid resorption of the facial bone wall following restoration. ${ }^{[12-14]}$ If this minimal requirement is not met, bone augmentation procedures are recommended to achieve an adequate bony contour. ${ }^{[14]}$ The initial thickness of the facial bone walls in the anterior maxilla result in additional local bone augmentation in the majority of implant sites in the jaw. ${ }^{[15]}$ However, information regarding facial bone thickness in various regions of the maxilla and mandible is scarce. Preoperative diagnostic procedures and risk assessments often include a three-dimensional radiographic analysis of the local bone anatomy. Today, cone beam computed tomography (CBCT) is preferred, since this new technology is noninvasive offers better image quality and lower radiation exposure with financial advantage and allows full three dimensional characterization of alveolar bone micro millimeter accuracy for linear measurements than conventional computed tomography (CT). ${ }^{[1,2]}$

The previous hypotheses were that there would be variability in thickness of facial bone wall at various tooth positions in the anterior maxilla and that age and sex would not influence the findings. [4]

The purpose of this retrospective radiographic study was to evaluate the thickness of the facial bone of teeth in the anterior maxilla based on CBCT images so as to give a better judgment regarding implant placement.

\section{Material and Methods}

The research was carried out on 90 single rooted teeth of 45 CBCT images collected from different imaging centers with age ranged between $20-55$ years including 20 females and 25 males; using the DICOM file of CBCT image which were transferred in On Demand 3Dwmv software (Version:1.0.10)

All the sections will be of 3-D images. The width and length measurements will be made at different levels with the help of the measurement tool in CS 3D software of the CBCT scan as the measurement technique.

The sections were of $75 \mu \mathrm{m}$ and $200 \mu \mathrm{m}$ having the exposure condition $60-90 \mathrm{kVp}$ and $550 \mathrm{~mA}$.

The subjects had all maxillary anterior teeth without obvious periodontal disease. The center of 
each tooth was measured on the sagittal and horizontal plane.

Measurements in the study showed as below.

From the 3D images, five aspects of the measurements were recorded by using On Demand 3D. Distance between cementoenamel junction (CEJ) and buccal bone crest, thickness of buccal and palatal plates, root diameter, buccal bony curvature angle below root apex and distance from root apex to the deepest point of buccal bony curvature were statistically analyzed on each maxillary anterior tooth.

The mean thickness of buccal and palatal alveolar plate on reference lines Four reference lines were used and all of them were perpendicular to the axis of each tooth. Line A was drawn at $3 \mathrm{~mm}$ below CEJ, line B was drawn at $4.5 \mathrm{~mm}$ below $\mathrm{CEJ}$, line $\mathrm{C}$ was drawn at the midpoint between CEJ and root apex, and line D was drawn at root apex. The thickness of buccal and palate alveolar plates was measured at reference lines.

Root diameter of the maxillary central incisor, lateral incisor and canine Mesio-distal and buccolingual diameter of each root was measured at reference line $\mathrm{A}$.

Buccal bony curvature angle $(\angle \mathrm{PQR})$ below the root apex, three reference points was used $(\mathrm{P}, \mathrm{Q}$, and $\mathrm{R}$ hereafter). Reference point $\mathrm{P}$ is the upper most and anterior part of buccal plate, point $\mathrm{R}$ is the one on buccal plate which meets with reference line $\mathrm{D}$, and point $\mathrm{Q}$ is the deepest point on the buccal bony curvature between $\mathrm{P}$ and $\mathrm{R}$. The angle formed by the points was measured.

The distance between root apex and the deepest point (Q) of buccal bony curvature the distance from line $\mathrm{D}$ to point $\mathrm{Q}$ was vertically measured.

Statistical analysis

All the data were statistically analyzed using simple t-test and one-way ANOVA. The significance level was set at $\alpha=0.05$. SPSS version 19.0and used for statistical analysis.

\section{Results}

The mean distance between CEJ and buccal bone crest the mean distance between CEJ and buccal bone crest was $1.99 \pm 0.59 \mathrm{~mm}$ in central incisor, $2.16 \pm 0.55 \mathrm{~mm}$ in lateral incisor and $2.51 \pm 0.5$ $\mathrm{mm}$ in canine. Generally, buccal bone crest of maxillary anterior teeth existed within $3 \mathrm{~mm}$ from CEJ (Table 1).

The thickness of buccal and palatal plate of maxillary anterior teeth The mean thickness of buccal plate at each maxillary anterior tooth in reference line A ( $3 \mathrm{~mm}$ below CEJ) was 0.59 $\pm 0.27 \mathrm{~mm}$ of central incisor, $0.69 \pm 0.54 \mathrm{~mm}$ of lateral incisor, and $1.05 \pm 0.75 \mathrm{~mm}$ of canine. Generally, each thickness of buccal plate in central incisor, lateral incisor and canine was very thin in reference line $\mathrm{A}$ and $\mathrm{C}$ (Table 2).

The mean thickness of palatal plate at each maxillary anterior tooth in reference line a $(3 \mathrm{~mm}$ below CEJ) was $1.23 \pm 0.45 \mathrm{~mm}$ of central incisor, $1.04 \pm 0.59 \mathrm{~mm}$ of lateral incisor, and 1.49 $\pm 0.61 \mathrm{~mm}$ of canine. Each thickness of the palatal plate in central incisor, lateral incisor and canine was statistically significantly thicker than that of the buccal plate and gradually increased from line A to line D (Table 3).

Root diameter of the maxillary anterior teeth At 3 $\mathrm{mm}$ below CEJ, the large value was showed in the diameter of the root, in order of canine, central incisor and lateral incisor (Table 4).

Buccal bony curvature angle $(\angle \mathrm{PQR})$ below root apex of maxillary anterior teeth Buccal bony curvature angle $(\angle \mathrm{PQR})$ below root apex was 114 $\pm 16.5 ®$ at central incisor, $144.0 \pm 12.9$ at lateral incisor, $145.0 \pm 8.9 \AA$ at canine. The smallest value was shown in buccal bony curvature angle of maxillary central incisor, which means that central incisor is most curved (Table 5).

The distance between root apex and the deepest point $(\mathrm{Q})$ of buccal bony curvature the distances between root apex and the deepest point $(\mathrm{Q})$ of buccal bony curvature were $3.49 \pm 1.17 \mathrm{~mm}$ at central incisor, $3.78 \pm 1.45 \mathrm{~mm}$ at lateral incisor, and $5.51 \pm 1.66 \mathrm{~mm}$ at canine. The distance between root apex and the deepest point (Q) of buccal bony curvature in canine was significantly larger than that of lateral and central incisor (Table 6). 
Table 1 The mean distance between CEJ and buccal bone crest (unit: $\mathrm{mm}$ )

\begin{tabular}{|l|c|c|c|c|}
\hline CEJ- Buccal bone crest & $\mathbf{N}$ & Central Incisor & Lateral Incisor & Canine \\
\hline
\end{tabular}

Table 2. The mean thickness of buccal plate of maxillary anterior teeth (unit: $\mathrm{mm}$ )

\begin{tabular}{|l|c|c|c|c|}
\hline $\begin{array}{l}\text { Site } \\
\text { Reference line }\end{array}$ & N & Central Incisor & Lateral Incisor & Canine \\
\hline A & 90 & $0.59 \pm 0.27$ & $0.69 \pm 0.54$ & $1.05 \pm 0.75$ \\
\hline B & 90 & $0.64 \pm 0.23$ & $0.69 \pm 0.60$ & $1.41 \pm 0.69$ \\
\hline C & 90 & $0.59 \pm 0.25$ & $0.54 \pm 0.76$ & $1.16 \pm 0.84$ \\
\hline D & 90 & $0.63 \pm 0.16$ & $0.79 \pm 1.17$ & $0.89 \pm 0.45$ \\
\hline
\end{tabular}

Table 3. The mean thickness of palatal plate of maxillary anterior teeth (unit: $\mathrm{mm}$ )

\begin{tabular}{|l|c|c|c|c|}
\hline $\begin{array}{l}\text { Site } \\
\text { Reference line }\end{array}$ & $\mathbf{N}$ & Central Incisor & Lateral Incisor & Canine \\
\hline A & 90 & $1.23 \pm 0.45$ & $1.04 \pm 0.59$ & $1.49 \pm 0.61$ \\
\hline B & 90 & $1.88 \pm 0.64$ & $1.22 \pm 0.67$ & $2.33 \pm 1.07$ \\
\hline C & 90 & $2.55 \pm 0.45$ & $1.34 \pm 0.60$ & $2.67 \pm 1.33$ \\
\hline D & 90 & $5.38 \pm 2.33$ & $3.72 \pm 1.59$ & $7.11 \pm 2.71$ \\
\hline
\end{tabular}

Table 4.Root diameter of the maxillary anterior teeth (unit: $\mathrm{mm}$ )

\begin{tabular}{|l|c|c|c|c|}
\hline Bucco lingual CEJ & N & Central Incisor & Lateral Incisor & Canine \\
\hline Mesio distal CEJ & 90 & $6.59 \pm 0.49$ & $6.11 \pm 0.65$ & $6.34 \pm 0.21$ \\
\hline Bucco lingual & 90 & $5.33 \pm 0.78$ & $5.14 \pm 0.59$ & $6.44 \pm 0.45$ \\
\hline [3mm below CEJ] & 90 & $5.38 \pm 0.76$ & $4.58 \pm 0.86$ & $5.34 \pm 0.22$ \\
\hline $\begin{array}{l}\text { Mesiodistal } \\
\text { [3mm below CEJ] }\end{array}$ & 90 & $4.66 \pm 0.39$ & $4.09 \pm 0.45$ & $5.27 \pm 0.52$ \\
\hline
\end{tabular}

Table 5 Buccal bony curvature angle $(\angle \mathrm{PQR})$ below root apex of maxillary anterior teeth (unit: ${ }^{\circ}$ )

\begin{tabular}{|l|c|c|c|c|}
\hline & N & Central Incisor & Lateral Incisor & Canine \\
\hline PQR[®] & 90 & $114 \pm 16.5$ & $144.0 \pm 12.9$ & $145.0 \pm 8.9$ \\
\hline
\end{tabular}

Table 6.The distance between root apex and the deepest point $(\mathrm{Q})$ of buccal bony curvature.(unit: ${ }^{\circ}$ )

\begin{tabular}{|l|c|c|c|c|}
\hline Root apex -Q point & $\mathbf{N}$ & Central Incisor & Lateral Incisor & Canine \\
\hline
\end{tabular}

\section{Discussion}

Long-term stability of implant system including adjutant gingival margins and teeth around implants and can be guaranteed by facial bone with sufficient thickness and height. ${ }^{[8,9]}$ Generally, buccal bony crest of maxillary anterior teeth existed within 2-3 mm from CEJ which support the theory that implant head should be at least 3 $\mathrm{mm}$ apical to an imaginary line connecting the cement enamel junctions (CEJs) of the adjacent teeth. ${ }^{[10]}$ With respect to the reference lines A, B, $\mathrm{C}$ and $\mathrm{D}$, the thickness of buccal plate in central incisor, lateral incisor and canine was all less than $1 \mathrm{~mm}$, which support the theory that implant platform should be placed more palatally because the buccal alveolar bone plate of North Indian adult is generally within $1 \mathrm{~mm}$. It is important to place the axis of the implant corresponding to the incisal edges of the adjacent teeth or slightly palatal to this landmark which leads to the chances of perforation. ${ }^{[11,12]}$. Kan and Rungcharassaeng ${ }^{[13]}$ stated that primary stability of implant is achieved by engaging the palatal wall and bone approximately $4 \mathrm{~mm}$ to $5 \mathrm{~mm}$ beyond the apex in 
socket. This also requires more pressing the drills against the palatal wall of the socket during the sequential osteotomy. Bone grafting is frequently done in case of thin facial bone to prevent collapse and minimize resorption. The final implant diameter was within the confines of the tooth socket, without engaging the coronal portion of the labial plate, which is generally thin, to prevent perforation. A average distance of 2-3 mm between the implant and adjacent teeth is required to minimize marginal bone loss ${ }^{[13]}$ When this is not possible, an augmentation procedure is necessary prior to or during implant placement. ${ }^{[14,15]}$ The suggested diameter for implants in the central incisor and canine areas is approximately $5-6 \mathrm{~mm}$, and lateral incisors is approximately $3-4 \mathrm{~mm} .^{[16,17]}$ At $3 \mathrm{~mm}$ below CEJ, the diameter of the root shows a large value in order of canine, central incisor and lateral incisor in size. Therefore, wide neck implants are not recommended for the use in the anterior maxilla. Also, the narrow neck implant which is most often recommended in lateral incisor areas was recommended due to the small diameter in North Indian adults. Buser et all suggested that the narrow neck implant with a shoulder diameter of $3.5 \mathrm{~mm}$ is most often used in lateral incisor areas with a minimal gap size of $5.5 \mathrm{~mm}$. In this study, buccal bony curvature angle $(\angle \mathrm{PQR})$ below root apex of maxillary central incisor was the smallest, and it indicates that the facial bony plate of central incisor below root apex is most curved. Thus the long axis of the drill during surgical drilling procedure in the central incisor should be parallel to buccal alveolar plate to prevent perforation of the facial plate. Also a thinner implant is recommended. In case of immediate implant placement following tooth extraction, the length of implant fixture should be as long as possible for initial stability. ${ }^{[18]}$ In this study, the mean distance between root apex and the deepest point of buccal bony curvature was $3.49 \pm 1.17 \mathrm{~mm}$ in central incisor, $3.78 \pm 1.45 \mathrm{~mm}$ in lateral incisor and $5.51 \pm 1.66 \mathrm{~mm}$ in canine. The labial bone profile is also more curved at the central incisor, in individuals with retruded maxillae in particular, so the apex of implant should be angulated palatally to avoid the perforation of labial bone at the apical region.

\section{Conclusion}

Within the limitation of this study in North Indian adults, the thickness of maxillary anterior buccal plate was very thin within $1.5 \mathrm{~mm}$ and the thickness of palatal plate was thick. The Buccal bony curvature below root apex of maxillary central incisor was higher than that of lateral incisor and canine and it seems that the buccal bony plate below root apex of central incisor is most curved. As this study was performed on limited number of CBCT images, a large sample will be required to get an exact conclusion.

\section{References}

1. Lee SL, Kim HJ, Son MK, Chung $\mathrm{CH}$, Anthropometric analysis of maxillary anterior buccal bone of Korean adults using cone-beam CT, J Adv Prosthodont 2010;2:92-6.

2. Buser D, Martin W, Belser UC. Optimizing esthetics for implant restorations in the anterior maxilla: anatomic and surgical considerations. Int $\mathbf{J}$ Oral Maxillofac Implants 2004; 19:43-61.

3. Nevins M, Camelo M, De Paoli S, Friedland B, Schenk RK, Parma-Benfenati S, Simion M, Tinti C, Wagenberg B. A study of the fate of the buccal wall of extraction sockets of teeth with prominent roots. Int J Periodontics Restorative Dent 2006; 26:19-29.

4. Cardaropoli G, Arau'jo M, Lindhe J. Dynamics of bone tissue formation in tooth extraction sites. An experimental study in dogs. J Clin Periodontol 2003; 30:809-18.

5. Johnson K. A study of the dimensional changes occurring in the maxilla after tooth extraction. Part 2: Closed face 
immediate denture treatment. Aust Dent J 1964; 9:6-13.

6. Arau'jo MG, Lindhe J. Dimensional ridge alterations following tooth extraction. An experimental study in the dog. J Clin Periodontol 2005; 32:212-8.

7. Schropp L, Wenzel A, Kostopoulos L, Karring T. Bone healing and soft tissue contour changes following single-tooth extraction: a clinical and radiographic 12month prospective study. Int $\mathrm{J}$ Periodontics Restorative Dent 2003; 23:313-23.

8. Swasty D, Lee JS, Huang JC, Maki K, Gansky SA, Hatcher D, Miller AJ. Anthropometric analysis of the human mandibular cortical bone as assessed by cone-beam computed tomography. J Oral Maxillofac Surg 2009; 67:491-500.

9. Belser UC, Buser D, Hess D, Schmid B, Bernard JP, Lang NP. Aesthetic implant restorations in partially edentulous patientsa critical appraisal. Periodontol 2000 1998; 17:132-50.

10. Buser D, von Arx T. Surgical procedures in partially edentulous patients with ITI implants. Clin Oral Implants Res 2000; 11:83100.

11. Langer B, Sullivan DY. Osseo integration: its impact on the interrelationship of periodontics and restorative dentistry. Part 3. Periodontal prosthesis redefined. Int $\mathbf{J}$ Periodontics Restorative Dent 1989; 9:240-61.

12. Becker W, Sennerby L, Bedrossian E, Becker BE, Lucchini JP. Implant stability measurements for implants placed at the time of extraction: a cohort, prospective clinical trial. J Periodontol 2005;76:391-7.

13. London RM. The esthetic effects of implant platform selection. Compend Contin Educ Dent 2001;22:675-82.

14. Kan JYK, Rungcharassaeng K. Immediate placement and provisionalization of maxillary anterior single implants: a surgical and prosthodontics rational. Pract Periodontics Aesthet Dent 2000; 12:81724.

15. Smukler H, Castellucci F, Capri D. The role of the implant housing in obtaining aesthetics: generation of peri-implant gingivae and papillae-Part 1. Pract Proceed Aesthet Dent 2003; 15:141-9.

16. Esposito M, Ekestubbe A, Gro "ndahl K. Radiological evaluation of marginal bone loss at tooth surfaces facing single Branemark implants. Clin Oral Implants Res 1993; 4:151-7.

17. Garber DA, Salama MA, Salama H. Immediate total tooth replacement. Compend Contin Educ Dent 2001; 22:2106, 218.

18. Saadoun AP, Le Gall MG. Periodontal implications in implant treatment planning for aesthetic results. Pract Periodontics Aesthet Dent 1998; 10:655-64.

19. Gelb DA. Immediate implant surgery: three-year retrospective evaluation of 50 consecutive cases. Int $\mathbf{J}$ Oral Maxillofac Implants 1993; 8:388-99. 